\title{
Sternum length and rib cage dimensions compared with bodily proportions in adults with cystic fibrosis
}

\author{
Louis-Philippe Laurin MD FRCPC, Vincent Jobin MD FRCPC, François Bellemare PhD
}

L-P Laurin, V Jobin, F Bellemare. Sternum length and rib-cage dimensions compared with bodily proportions in adults with cystic fibrosis. Can Respir J 2012;19(3):196-200.

BACKGROUND: A greater structural expansion of the rib cage in females compared with males has been described in cystic fibrosis (CF) patients; however, conflicting data exist as to whether an elongation of the bony ribs and sternum contributes to this expansion.

OBJECTIVES: To compare height-adjusted anthropometric measures and sternum length between a group of normal subjects and a group of CF patients of both sexes.

METHODS: Anthropometric measurements including body weight, height, upper and lower limb lengths, biacromial distance and pelvic width were measured in the standing position in $30 \mathrm{CF}$ patients (13 males) and 28 normal subjects (14 males). Body surface measurements of anterior-posterior and lateral diameters of the rib cage at functional residual capacity, and sternum length were also obtained.

RESULTS: Compared with normal subjects, CF patients had lower body weight, shorter standing height and shorter height-adjusted upper and lower limb lengths. Rib cage diameters were greater in CF patients than in normal subjects of either sex, but height-adjusted sternum length was not different.

CONCLUSION: Significant differences in bodily proportions were found between normal subjects and CF patients, suggesting a differential growth pattern for the trunk and limbs. However, increased rib cage dimensions with lung hyperinflation and airway obstruction was not associated with an elongation of the sternum.

Key Words: Biometrics; Chest wall; Cystic fibrosis in adults; Lung hyperinflation; Sternum length

Tn spite of substantial improvements in care and survival in patients 1 with cystic fibrosis (CF), a sex gap in mortality persists, with survival being three to five years shorter in females than in males $(1,2)$. A sex difference in thoracic adaptation to pulmonary hyperinflation has been described in CF patients: rib cage cross-sectional area for a given rib inclination was shown to be greater in CF patients than in normal subjects, indicating a structural expansion of the rib cage that is 2.5 times greater in females than in males (3). A structural expansion of the rib cage may impair diaphragm function and increase the energy cost of breathing, which may contribute to more rapid respiratory failure in female than in male CF patients. Because pulmonary hyperinflation can occur during the growth period of patients with $\mathrm{CF}$, it is conceivable that it may favour an outgrowth of the bony rib cage. Because the ribs tend to grow longer in relation to height in females than in males, it is also conceivable that this outgrowth could be greater in female than in male CF patients (4). An elongation of the ribs and sternum has been described in an animal model of hyperinflation (5). Available data in human CF patients are scarce and conflicting. A longer sternum length has been described in children with CF compared with normal children of the same height (6), although no distinction between the sexes was made in that study. However, a more recent study (7) found no significant difference in the length of the sixth rib and sternum between adult male CF patients and normal subjects (7).

\section{La longueur du sternum et les dimensions de la cage thoracique par rapport aux proportions du corps chez les adultes ayant la fibrose kystique}

HISTORIQUE : On a décrit une plus grande expansion structurelle de la cage thoracique chez les patientes par rapport aux patients ayant la fibrose kystique (FK). Cependant, il existe des données conflictuelles pour établir si une élongation des os de la cage thoracique et du sternum contribue à cette expansion.

OBJECTIFS : Comparer les mesures anthropométriques et la longueur du sternum rajustées selon la taille entre un groupe de sujets en santé et un groupe de patients ayant la FK des deux sexes.

MÉTHODOLOGIE : Les chercheurs ont pris les mesures anthropométriques, y compris le poids corporel, la taille, la longueur des membres supérieurs et inférieurs, la distance biacromiale et la largeur du bassin, de 30 patients ayant la FK ( 13 de sexe masculin) et de 28 sujets en santé ( 14 de sexe masculin) en position debout. Ils ont également obtenu les mesures de la surface des diamètres antéro-postérieur et latéral de la cage thoracique à la capacité résiduelle fonctionnelle ainsi que la longueur du sternum.

RÉSULTATS : Par rapport à des sujets en santé, les patients ayant la FK avaient un poids corporel moins élevé, une taille moins élevée en position debout et une longueur des membres supérieurs et inférieurs rajustée selon le poids. Le diamètre de la cage thoracique était plus grand chez les patients ayant la FK que chez les sujets en bonne santé de l'un ou l'autre sexe, mais la longueur du sternum selon le poids n'était pas différente.

CONCLUSION : Les auteurs ont constaté des différences importantes des proportions corporelles entre les sujets en santé et les patients ayant la FK, ce qui laisse supposer un mode de croissance différentielle du tronc et des membres. Cependant, une plus grande dimension de la cage thoracique, accompagnée d'une hyperinflation pulmonaire et d'une obstruction des voies aériennes, ne s'associait pas à une élongation du sternum.

In the present study, we hypothesised that rib cage expansion with lung hyperinflation in CF patients would be associated with an elongated sternum, and that this would be more accentuated in females than in males.

\section{Subjects}

\section{METHODS}

Thirty CF patients (13 males and 17 females) were recruited among hospitalized patients and during CF ambulatory clinics in the same hospital. All patients had a stable respiratory condition. Recent pulmonary function test results, age at diagnosis and diagnostic data (genetic testing and/or sweat test) were noted from each patient's medical record. In addition, 28 age- and sex-matched normal subjects (14 males and 14 females) were recruited among hospital employees, medical students and medical residents. All normal subjects were nonsmokers without a history of thoracic trauma or surgery, and underwent a forced spirometry test (forced expiratory volume in $1 \mathrm{~s}\left[\mathrm{FEV}_{1}\right]$ and forced vital capacity [FVC]), the results of which had to be within normal limits. The protocol was approved by the human ethics committee of the Centre Hospitalier de l'Université de Montréal-Hôtel-Dieu (Montreal, Quebec). All participants provided written informed consent.

Assuming an isotropic elongation of rib cage bones of at least $5.3 \%$, corresponding to the increase in rib cage cross-sectional area at

Laboratoire du sommeil et clinique de fibrose kystique du Centre Hospitalier de l'Université de Montréal (CHUM) - Hôtel-Dieu, Montréal, Québec

Correspondence: Dr Vincent Jobin, Laboratoire du sommeil, CHUM-Hôtel-Dieu, 3840 St-Urbain, Montréal, Québec H2W 1 T8.

Telephone 450-647-5438, e-mail vincent.jobin@umontreal.ca 
TABLE 1

Physical and pulmonary function characteristics

\begin{tabular}{|c|c|c|c|c|c|c|}
\hline & \multicolumn{3}{|c|}{ Normal subjects } & \multicolumn{3}{|c|}{ Cystic fibrosis patients } \\
\hline & Males & Females & All & Males & Females & All \\
\hline Age $^{\star}$, years & $27.4 \pm 7.3$ & $24.1 \pm 3.4$ & $25.8 \pm 5.8$ & $29.1 \pm 7.3$ & $24.3 \pm 4.3$ & $26.4 \pm 6.2$ \\
\hline $\mathrm{BMI}^{\dagger}, \mathrm{kg} / \mathrm{m}^{2}$ & $23.1 \pm 2.0$ & $21.8 \pm 2.1$ & $22.5 \pm 2.1$ & $21.2 \pm 2.2^{\S}$ & $20.4 \pm 2.1$ & $20.8 \pm 2.2^{\ddagger}$ \\
\hline Height* ${ }^{*} \mathrm{~cm}$ & $179.1 \pm 6.3$ & $161.0 \pm 4.0$ & $170.1 \pm 10.5$ & $172.3 \pm 7.5^{\S}$ & $158.8 \pm 5.4^{\S}$ & $164.7 \pm 9.3^{\S}$ \\
\hline $\mathrm{FEV}_{1}{ }^{*}, \%$ predicted & $103.4 \pm 11.3$ & $108.2 \pm 13.1$ & $105.8 \pm 12.3$ & $54.9 \pm 21.5^{\ddagger}$ & $56.9 \pm 17.8^{\ddagger}$ & $56.0 \pm 19.2^{\ddagger}$ \\
\hline $\mathrm{FEV}_{1} / \mathrm{FVC}$ & $0.8 \pm 0.1$ & $0.9 \pm 0.04$ & $0.9 \pm 0.1$ & $0.6 \pm 0.1^{\ddagger}$ & $0.6 \pm 0.1^{\ddagger}$ & $0.6 \pm 0.1^{\ddagger}$ \\
\hline $\mathrm{RV}, \%$ predicted & N/A & $\mathrm{N} / \mathrm{A}$ & $\mathrm{N} / \mathrm{A}$ & $225.2 \pm 85.8$ & $234.5 \pm 81.1$ & $230.5 \pm 81.7$ \\
\hline TLC, \% predicted & N/A & N/A & N/A & $111.7 \pm 18.1$ & $113.1 \pm 16.3$ & $112.5 \pm 16.8$ \\
\hline
\end{tabular}

Data presented as group mean \pm SD. *Between-group comparisons based on Mann-Whitney two-sample statistic, other comparisons based on two-sample t test; ${ }^{\dagger}$ Data not available for two normal female subjects; ${ }^{\ddagger} P<0.005$ versus normal subjects; ${ }^{\S} P<0.05$. BMI Body mass index; FEV ${ }_{1}$ Forced expiratory volume in 1 s; FVC Forced vital capacity; N/A Not available ; RV Residual volume; TLC Total lung capacity

a given rib angle previously reported in male CF patients (3), and a mean ( \pm SD) sternum length of $17 \pm 1.7 \mathrm{~cm}$, it was estimated that 29 subjects per group would be necessary to detect such a difference in sternum length with a probability of 0.05 and a power of $80 \%$.

\section{Anthropometric measurements}

All measurements were obtained with the subjects standing upright. For each measurement, anatomical landmarks were first identified and marked on the skin with a pen. The following dimensions were measured twice on each of the subjects by the same medical resident (LPL), with the average value calculated and recorded.

Arm length: The lengths of the right and left arms were measured as the distance between the acromion and the ulnar styloid process with a metric tape. Measurements were taken with arms in abduction at $90^{\circ}$.

Leg length: The lengths of the right and left legs were measured as the distance between the iliac crest and the lateral malleolus using a metric tape.

Sternum length: Sternal length was measured as the distance between the sternal notch and the sternal-xiphisternal junction using a metric tape.

Biacromial distance: The distance between acromions was measured with a pelvic caliper.

Pelvis width: The distance between iliac crests was measured using a pelvic caliper.

Anterior-posterior rib cage diameters: The upper and lower anteriorposterior diameters of the chest at the level of the manubrium $\left(A P_{R_{C} U}\right)$ and sternal-xiphisternal junction $\left(\mathrm{AP}_{\mathrm{RC}}\right)$, respectively, were measured using a pelvic caliper at the end of a normal expiration.

Lateral rib cage diameter: The lateral diameter of the rib cage $\left(\mathrm{LA}_{\mathrm{RC}}\right)$ at the level of the xiphisternum was measured with the pelvic caliper at end-expiration.

Skinfold thickness: Skinfold thickness was measured at the level of the pelvis, at the level of the xiphisternum in the mid-axillary line and in the back between the shoulder blades using a standard skinfold caliper. These measurements were used to correct the values of pelvis width and of rib cage diameters measured with the pelvis caliper.

Height and weight: Height and weight were measured as part of the pulmonary function testing.

\section{Reproducibility}

Sternal length was measured twice on two separate occasions in 10 normal subjects. When expressed as a percentage of the values obtained in the first evaluation, the difference for the 10 paired observations averaged $0.4 \pm 3.36 \%$ and was not significantly different from zero.

Statistical analysis

In addition to the measurements just described, all dimensions were adjusted for height for statistical analysis. Between-group comparisons were performed with the two-sample $t$ test (with Welch correction for unequal variances) or the Mann-Whitney $U$ test when the data were not normally distributed. ANOVA was used for analysis of subgroups according to sex and disease severity. Statistical computations were conducted using SPSS version 16 (IBM Corporation, USA) for Macintosh (Apple Inc, USA). $\mathrm{P}<0.05$ was considered to be statistically significant.

\section{RESULTS}

Subjects characteristics

As shown in Table 1, age and sex distributions were comparable in the two groups. Patients in the CF group demonstrated significant airway obstruction and pulmonary hyperinflation ranging from mild to severe, as reflected by a lower $\mathrm{FEV}_{1} / \mathrm{FVC}$ ratio and elevated residual volume (RV), respectively. Furthermore, CF patients had shorter standing heights, lower body weights and lower body mass indexes (BMIs) than normal subjects. These between-group differences were comparable in males and females.

\section{Differences in linear dimensions}

Bodily dimensions: As shown in Table 2, with the exception of pelvis width, which was not significantly different between the two groups, all dimensions measured were significantly smaller in CF patients of either sex than in normal subjects.

Thoracic dimensions: $\mathrm{AP}_{\mathrm{RC}_{-} \mathrm{U}}$ and $\mathrm{AP}_{\mathrm{RC}_{-} \mathrm{L}}$ were significantly greater, and sternum length significantly shorter in $\mathrm{CF}$ patients than in normal subjects. $\mathrm{LA}_{\mathrm{RC}}$, however, was not significantly different between the two groups.

Differences in proportions: Bodily proportions: As shown in Table 3 , the ratios of arm length to standing height and of leg length to standing height were significantly smaller, whereas the ratio of pelvis width to standing height was significantly greater in CF patients than in normal subjects. The ratio of biacrominal distance to standing height was not significantly different between these two groups. These findings were comparable in males and females.

Thoracic proportions: The ratios of $\mathrm{AP}_{\mathrm{RC}_{\mathrm{U}}}, \mathrm{AP}_{\mathrm{RC} L}$ and $\mathrm{LA}_{\mathrm{RC}}$ to standing height were all significantly greater in $\mathrm{CF}$ patients than in normal subjects. However, the ratio of sternum length to standing height was not significantly different between the two groups. Similar results were obtained when the various measures listed in Table 2 were referenced against leg length rather than standing height. These findings were comparable in males and females.

Effects of disease severity on anthropometric dimensions: Due to the wide spectrum of disease severity among patients in the CF group, they were divided in two groups. Patients with $\mathrm{FEV}_{1}<60 \%$ of predicted were considered to have a severe obstructive disease and those with a 
TABLE 2

Body and rib cage dimensions

\begin{tabular}{|c|c|c|c|c|c|c|}
\hline & \multicolumn{3}{|c|}{ Normal subjects } & \multicolumn{3}{|c|}{ Cystic fibrosis patients } \\
\hline & Males & Females & All & Males & Females & All \\
\hline Patients, $\mathrm{n}$ & 14 & 14 & 28 & 13 & 17 & 30 \\
\hline Arm length, $\mathrm{cm}$ & $55.9 \pm 3.0$ & $50.1 \pm 1.3$ & $53.0 \pm 3.7$ & $52.8 \pm 2.4^{\dagger}$ & $48.4 \pm 2.2^{\ddagger}$ & $50.3 \pm 3.1^{\dagger}$ \\
\hline Biacromial distance, $\mathrm{cm}$ & $40.1 \pm 2.3$ & $34.9 \pm 1.3$ & $37.5 \pm 3.2$ & $38.0 \pm 2.1^{\dagger}$ & $33.8 \pm 1.7$ & $35.7 \pm 2.8^{\dagger}$ \\
\hline Pelvis width, $\mathrm{cm}$ & $25.5 \pm 1.3$ & $23.1 \pm 1.1$ & $24.3 \pm 1.7$ & $25.8 \pm 1.4$ & $23.8 \pm 1.8$ & $24.7 \pm 1.9$ \\
\hline $\mathrm{AP}_{\mathrm{RC} \_\mathrm{U}}, \mathrm{cm}$ & $16.2 \pm 1.2$ & $13.6 \pm 1.3$ & $14.9 \pm 1.8$ & $18.7 \pm 1.5^{\dagger}$ & $15.7 \pm 1.8^{\dagger}$ & $17.0 \pm 2.2^{\dagger}$ \\
\hline $\mathrm{LA}_{\mathrm{RC}}, \mathrm{cm}$ & $25.6 \pm 2.0$ & $21.7 \pm 1.3$ & $23.7 \pm 2.6$ & $24.6 \pm 1.7$ & $22.8 \pm 1.5$ & $23.6 \pm 1.8$ \\
\hline Sternum length, $\mathrm{cm}$ & $17.2 \pm 1.3$ & $16.1 \pm 1.8$ & $16.7 \pm 1.7$ & $16.5 \pm 1.4$ & $15.4 \pm 1.2$ & $15.9 \pm 1.4^{\ddagger}$ \\
\hline
\end{tabular}

Data presented as group mean $\pm S D$. *Between-group comparison based on Mann-Whitney two-sample statistic, all other comparisons based on two-sample $t$ test. ${ }^{\dagger} P<0.005$ versus normal subjects; ${ }^{\ddagger} P<0.05 . A P_{R C} L$ Diameter of the anteroposterior lower rib cage at the level of xiphisternum; $A P_{R C} U$ Diameter of the anteroposterior upper rib cage at the level of manubrium; $B M I$ Body mass index; $L A_{R C}$ Lateral diameter of the rib cage at the level of xiphisternum

TABLE 3

Height-adjusted body and rib cage dimensions

\begin{tabular}{|c|c|c|c|c|c|c|}
\hline & \multicolumn{3}{|c|}{ Normal subjects } & \multicolumn{3}{|c|}{ Cystic fibrosis patients } \\
\hline & Males & Females & All & Males & Females & All \\
\hline Patients, $n$ & 14 & 14 & 28 & 13 & 17 & 30 \\
\hline Arm length, $\mathrm{cm} \cdot \mathrm{m}^{-1}$ & $31.2 \pm 1.0$ & $31.1 \pm 0.6$ & $31.1 \pm 0.8$ & $30.6 \pm 0.6$ & $30.5 \pm 0.8^{\dagger}$ & $30.5 \pm 0.7^{\ddagger}$ \\
\hline Leg length, $\mathrm{cm} \cdot \mathrm{m}^{-1}$ & $56.6 \pm 0.9$ & $56.8 \pm 1.2$ & $56.7 \pm 1.1$ & $55.5 \pm 1.2^{\dagger}$ & $55.9 \pm 1.3^{\dagger}$ & $55.7 \pm 1.3^{\ddagger}$ \\
\hline Biacromial distance, $\mathrm{cm} \cdot \mathrm{m}^{-1}$ & $22.4 \pm 1.1$ & $21.7 \pm 0.9$ & $22.0 \pm 1.0$ & $22.1 \pm 1.1$ & $21.3 \pm 1.1$ & $21.7 \pm 1.2$ \\
\hline Pelvis width* ${ }^{*} \mathrm{~cm} \cdot \mathrm{m}^{-1}$ & $15.4 \pm 0.7$ & $15.8 \pm 0.3$ & $15.6 \pm 0.6$ & $15.9 \pm 0.7^{\dagger}$ & $16.3 \pm 1.1^{\dagger}$ & $16.1 \pm 0.9^{\ddagger}$ \\
\hline$A P_{R C \_U}, \mathrm{~cm} \cdot \mathrm{m}^{-1}$ & $9.9 \pm 0.6$ & $9.3 \pm 0.8$ & $9.6 \pm 0.8$ & $11.6 \pm 1.1^{\ddagger}$ & $10.8 \pm 1.3^{\ddagger}$ & $11.1 \pm 1.3^{\ddagger}$ \\
\hline $\mathrm{AP}_{\mathrm{RC} \mathrm{L}_{\mathrm{L}}}, \mathrm{cm} \cdot \mathrm{m}^{-1}$ & $7.9 \pm 0.7$ & $7.4 \pm 0.4$ & $7.6 \pm 0.6$ & $8.6 \pm 0.7^{\ddagger}$ & $8.2 \pm 0.9^{\ddagger}$ & $8.4 \pm 0.8^{\ddagger}$ \\
\hline $\mathrm{LA}_{\mathrm{RC}}, \mathrm{cm} \cdot \mathrm{m}^{-1}$ & $15 \pm 0.9$ & $14.4 \pm 0.8$ & $14.7 \pm 0.9$ & $14.8 \pm 1.0$ & $15.1 \pm 0.8^{\ddagger}$ & $15 \pm 0.9^{\dagger}$ \\
\hline Sternum length* ${ }^{*} \mathrm{~cm} \cdot \mathrm{m}^{-1}$ & $9.6 \pm 0.5$ & $10.0 \pm 1.2$ & $9.8 \pm 0.9$ & $9.6 \pm 0.7$ & $9.7 \pm 0.9$ & $9.7 \pm 0.8$ \\
\hline
\end{tabular}

Data presented as group mean \pm SD. All values are normalized for standing height in metres. *Between-group comparisons based on Mann-Whitney two-sample statistic, all other comparisons based on two-sample t test; ${ }^{\dagger} P<0.05$; ${ }^{\ddagger} P<0.005$ versus normal subjects. $A P_{R C} L$ Diameter of the anteroposterior lower rib cage at the level of xiphisternum; $A P_{R C_{-}}{ }$Diameter of the anteroposterior upper rib cage at the level of manubrium; $L A_{R C} L a t e r a l$ diameter of the rib cage at the level of xiphisternum

\section{TABLE 4}

Height-adjusted characteristics according to disease severity in cystic fibrosis patients

\begin{tabular}{|c|c|c|c|c|c|c|}
\hline & \multicolumn{3}{|c|}{$\mathrm{FEV}_{1} \geq 60 \%$ predicted } & \multicolumn{3}{|c|}{ FEV $_{1}<60 \%$ predicted } \\
\hline & Males & Females & All & Males & Females & All \\
\hline Patients, $\mathrm{n}$ & 7 & 9 & 16 & 6 & 8 & 14 \\
\hline Age, years & $25 \pm 5.9$ & $24.6 \pm 5.3$ & $24.8 \pm 5.4$ & $33.8 \pm 6.3^{*}$ & $24 \pm 3.5$ & $28.2 \pm 6.9$ \\
\hline $\mathrm{FEV}_{1}, \%$ predicted & $71.9 \pm 9.4$ & $72 \pm 3.1$ & $71.9 \pm 6.4$ & $35.2 \pm 11.6$ & $39.9 \pm 9.6$ & $37.9 \pm 10.4$ \\
\hline FVC, \% predicted & $89.1 \pm 13.7$ & $86.6 \pm 7.9$ & $87.7 \pm 10.5$ & $57.8 \pm 12.6$ & $64.3 \pm 17.6$ & $61.5 \pm 15.5$ \\
\hline Height, m & $1.76 \pm .07$ & $1.6 \pm .06$ & $1.67 \pm .1$ & $1.68 \pm .07^{*}$ & $1.57 \pm .05$ & $1.61 \pm .08$ \\
\hline Arm length, $\mathrm{cm} \cdot \mathrm{m}^{-1}$ & $30.7 \pm 0.7$ & $30.5 \pm 0.6$ & $30.6 \pm 0.6$ & $30.6 \pm 0.4$ & $30.4 \pm 1.1$ & $30.5 \pm 0.8$ \\
\hline Leg length, $\mathrm{cm} \bullet \mathrm{m}^{-1}$ & $55.9 \pm 1.2$ & $56.5 \pm 0.7$ & $56.2 \pm 1$ & $55 \pm 1.1$ & $55.2 \pm 1.6^{\star \star}$ & $55.1 \pm 1.3^{\star *}$ \\
\hline Biacromial distance, $\mathrm{cm} \cdot \mathrm{m}^{-1}$ & $21.3 \pm 0.7$ & $21 \pm 1.2$ & $21.1 \pm 1$ & $23 \pm 0.7^{\star \star \star}$ & $21.6 \pm 1.0$ & $22.2 \pm 1.1^{\star *}$ \\
\hline Pelvis width, $\mathrm{cm} \cdot \mathrm{m}^{-1}$ & $16 \pm 0.6$ & $16.2 \pm 1.1$ & $16.1 \pm 0.9$ & $15.8 \pm 0.7$ & $16.3 \pm 1.1$ & $16.1 \pm 1$ \\
\hline $\mathrm{AP}_{\mathrm{RC} \mathrm{U}}, \mathrm{cm} \cdot \mathrm{m}^{-1}$ & $10.9 \pm 1.1$ & $10.2 \pm 1.1$ & $10.5 \pm 1.1$ & $12.3 \pm 0.7^{*}$ & $11.4 \pm 1.3^{*}$ & $11.8 \pm 1.1^{\star *}$ \\
\hline 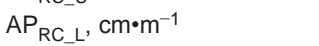 & $8.3 \pm 0.7$ & $7.9 \pm 0.6$ & $8.1 \pm 0.6$ & $8.9 \pm 0.6$ & $8.7 \pm 0.9$ & $8.8 \pm 0.8^{*}$ \\
\hline $\mathrm{LA}_{\mathrm{RC}}, \mathrm{cm} \cdot \mathrm{m}^{-1}$ & $14.8 \pm 1.2$ & $15.1 \pm 0.8$ & $15 \pm 1$ & $14.8 \pm 0.7$ & $15.2 \pm 0.8$ & $15 \pm 0.8$ \\
\hline Sternum length, $\mathrm{cm} \cdot \mathrm{m}^{-1}$ & $9.4 \pm 0.6$ & $9.6 \pm 0.9$ & $9.5 \pm 0.8$ & $9.8 \pm 0.7$ & $9.9 \pm 0.9$ & $9.8 \pm 0.8$ \\
\hline
\end{tabular}

Data presented as mean $\pm S D$. Between-group comparisons based on two-sample $t$ test with Welch correction for unequal variances. ${ }^{\star} P<0.05$; ${ }^{\star} P<0.01 ;{ }^{* \star *} P<0.005$ $A P_{R C_{-} L}$ Diameter of the anteroposterior lower rib cage at the level of xiphisternum; $A P_{R C_{-} U}$ Diameter of the anteroposterior upper rib cage at the level of manubrium; FEV ${ }_{1}$ Forced expiratory volume in $1 \mathrm{~s}$; FVC Forced vital capactiy; $L A_{R C}$ Lateral diameter of the rib cage at the level of xiphisternum

$\mathrm{FEV}_{1} \geq 60 \%$ of predicted to have mild to moderate disease. The results are summarized in Table 4. In all comparisons, the interaction term between the group category and sex were included in the ANOVA model. In the case of age, this interaction term was significant $(\mathrm{P}=0.02$ [ANOVA] $)$ because male patients in the severe group were significantly older than those in the less-severe group, whereas no such difference was found in females. In all other comparisons, the interaction terms between the severity group and sex were not significant, indicating comparable between-group differences in males and females. The ratios of arm lengths to standing height and of pelvis width to standing height did not differ significantly between the two severity groups $(\mathrm{P}>0.6[\mathrm{ANOVA}])$. However, the ratio of leg lengths to standing height was significantly smaller ( $\mathrm{P}=0.01$ [ANOVA] $)$ and the ratio of biacromial distance to standing height significantly greater $(\mathrm{P}=0.002[\mathrm{ANOVA}])$ in the more severe group than in the less severe group. The ratios of $\mathrm{AP}_{\mathrm{RC}_{-} \mathrm{U}}(\mathrm{P}=0.003$ [ANOVA] $)$ and $A P_{\mathrm{RC}_{-} \mathrm{L}}$ 
( $\mathrm{P}=0.01[\mathrm{ANOVA}])$ to standing height were both significantly greater in the more severe group than in the less severe group. In contrast, the ratios of $\mathrm{LA}_{\mathrm{RC}}$ to standing height and of sternum length to standing height were not significantly different between the two severity groups $(\mathrm{P}>0.3$ [ANOVA] $)$.

\section{DISCUSSION}

The present study demonstrated no significant difference in heightadjusted sternum length between normal subjects and CF patients of either sex or disease severity in spite of these patients having moderate to severe signs of pulmonary hyperinflation with increased rib cage dimensions. Several differences in bodily proportions were found between normal subjects and CF patients, suggesting differential effects of growth retardation in CF patients.

The results of the present study are consistent with those of previous studies showing greater rib cage dimensions in CF patients with pulmonary hyperinflation compared with normal subjects $(3,8,9)$. Contrary to our expectations, however, this was not associated with an outgrowth of the sternum in relation to height. It has been previously shown that for any given dorsoventral inclination of the ribs, the cross-sectional area of the rib cage is greater in CF patients than in normal subjects and that this is more accentuated in females than in males (3). These findings have been interpreted as reflecting an adaptative structural expansion of the rib cage in response to pulmonary hyperinflation presumably caused by an elongation of the ribs and/or costal cartilages. In the present study, we hypothesized that an outgrowth of the sternum would also contribute, which is not what was found. Our results in humans differ from those obtained in an animal model of pulmonary hyperinflation, which showed proportionate elongations of the ribs, sternum and costal cartilages, with increases in lung size (5). The presumed isotropism of rib cage expansion observed in this animal model clearly does not apply to patients in the present study.

Our results also differ from a previous study involving humans showing a longer sternum length in relation to height in patients with CF compared with normal subjects (6). The same methodology was used in these two studies with comparable reproducibility. Technical factors, therefore, are unlikely to account for the different results. The study by deMuth et al (6), published 45 years ago, was conducted in $22 \mathrm{CF}$ patients with ages ranging from four to 22 years. Over the past four decades, we contributed to the impressive improvement in the care of CF patients, mainly through systematic follow-up through specialized multidisciplinary clinics and the introduction of more efficacious therapy. Between 1985 and 2007, the median survival age increased from approximately 27 to 37 years (10). This improved care could also have caused modifications in the pattern of growth associated with CF, which in turn may explain the different results. Indeed, as the present study showed, CF patients tend to have shorter legs (and arms) in relation to height than normal subjects, indicating a relative sparing of trunk growth compared with that of the limbs (Table 2) (more about the latter below). Such a differential pattern of growth would tend to increase sternum length in relation to height in CF patients. A modification of this pattern of growth with improved care could thus explain the observed differences between the present study and that of DeMuth et al (6).

The results of the present study are consistent with those of a previous study by Guignon et al (7) involving a small group of male CF patients after heart-lung transplantation that showed no significant difference in sternum length between CF patients and age-, sex- and height-matched normal subjects. Our conclusions are based on a much larger group of patients, conferring more powerful statistical significance to these results. As described by Gray (11), sternal growth is complex and heterogeneous, typically beginning in fetal life and ending after puberty. Three patterns of ossification have been described (12), and mechanical forces may strongly influence sternal growth, morphology and development (13). Pulmonary hyperinflation and rib cage expansion were clearly present in CF patients and of comparable magnitude to those in our previous study (Table 2) (3). It is possible that the radial expansion of the lungs and rib cage with pulmonary hyperinflation in CF patients may impose a less severe stress on the sternum than on the ribs and/or costal cartilages. It is worth noting that in the study by Guignon et al (7), the length of the sixth rib was slightly longer, albeit not significantly (ie, approximately 6\%) in CF patients than in the normal controls. Considering the small number of subjects studied by Guignon et al $(n=4)$, and the fact that they were all males, additional measurements could be worth pursuing because a structural enlargement of the rib cage may have important clinical implications (3).

While impaired growth associated with CF has been noted for years with, for example, one-third of children with CF reported in the 1993 National CF Patient Registry below the 10th percentile for height and weight (14), it has not been previously appreciated that the growth of limbs and trunks could be affected differently. Major factors that impair growth, such as malnutrition, chronic inflammation and corticosteroid treatment, do so by interacting with the growth hormone $(\mathrm{GH})$ /insulin-like growth factor-1 (IGF-1) axis (15). A short stature caused by deletion of a $\mathrm{GH}$ gene in a CF patient has been also described (16). Schnabel et al (17) have recently shown an increased growth velocity in CF patients treated with GH compared with controls, reflecting the major role of $\mathrm{GH}$ in growth. However, only height growth was studied. Based on our findings, we suppose that GH/IGF-1 deficit not only can affect height and weight growth, but also possibly limbs growth to a greater extent than that of the trunk. In fact, a slower limb (arms and legs) growth in relation to that of the trunk has been described in patients with GH deficiency (18) as well as in patients with abnormal growth velocity associated with a SHOX (Short stature homeobox-containing gene) mutation (19). A lower level of physical activity may also contribute to limit limb growth relative to that of the trunk.

The present study has several limitations. All measurements were made by the same observer because none required substantial interpretation and a satisfactory day-to-day reproducibility of the primary outcome measure was demonstrated. Body surface measurements, particularly those of rib cage dimensions, are less accurate than measurements obtained using other techniques, such as $\mathrm{x}$-rays or spiral computed tomography scanning (7) because they include chest wall thickness. A partial correction of these measurements was obtained by subtracting skinfold thickness as a way to correct for intersubject differences in adiposity. Furthermore, differences in thoracic dimensions observed here between males and females or between CF patients and normal subjects (Table 2) were comparable with those previously reported using chest $\mathrm{x}$-rays (3). Thus, we believe the present comparisons are valid.

\section{CONCLUSION}

The present study showed significant differences in several bodily proportions in CF patients compared with normal subjects. Specifically, CF patients were found to have shorter limbs in relation to standing height than normal subejcts, suggesting a relative preservation of trunk growth. We also showed that increased rib cage dimensions in CF patients with lung hyperinflation cannot be accounted for by an outgrowth of the sternal bone. More studies are needed to clarify the mechanisms of thoracic adaptation to pulmonary hyperinflation in patients with CF to better understand their impact on respiration.

ACKNOWLEDGEMENTS: The authors thank the personnel of the respirology department at Hôtel-Dieu for their help with patient recruitment, as well as Nadia Beaudoin and Lara Bilodeau for their help in measurements.

DISCLOSURES: FB was supported by Medigas, OSR Medical and the Laboratoires Biron, Montreal, Quebec. 


\section{REFERENCES}

1. Rosenfeld M, Davis R, FitzSimmons S, Pepe M, Ramsey B. Gender gap in cystic fibrosis mortality. Am J Epidemiol 1997;145:794-803.

2. Davis PB. The gender gap in cystic fibrosis survival. J Gend Specif Med 1999;2:47-51.

3. Bellemare F, Jeanneret A. Sex differences in thoracic adaptation to pulmonary hyperinflation in cystic fibrosis. Eur Respir J 2007:29:98-107.

4. Bellemare F, Fuamba T, Bourgeault A. Sexual dimorphism of human ribs. Respir Physiol Neurobiol 2006;150:233-9.

5. Thomas AJ, Supinski GS, Kelsen SG. Changes in chest wall structure and elasticity in elastase-induced emphysema. J Appl Physiol 1986;61:1821-9.

6. Demuth GR, Howatt WF, Hill BM. The growth of lung function. Pediatrics 1965;35(Suppl):159-218.

7. Guignon I, Cassart M, Gevenois PA, et al. Persistent hyperinflation after heart-lung transplantation for cystic fibrosis. Am J Respir Crit Care Med 1995;151:534-40.

8. Bellemare JF, Cordeau MP, Leblanc P, Bellemare F. Thoracic dimensions at maximum lung inflation in normal subjects and in patients with obstructive and restrictive lung diseases. Chest 2001;119:376-86.

9. Stamm SJ, Docter J. Chest measurements as an aid in the diagnosis of cystic fibrosis. Dis Chest 1965;47:98-101.

10. Foundation CF. Patient Registry 2007 Annual Data Report. Bethesda: Cystic Fibrosis Foundation, 2008.

11. Gray H. Osteology. In: Williams P, Warwick R, Dyson M, Bannister L, eds. Gray's anatomy, 37th edn. New York: Churchill Livingstone, 1989:331-3.
12. Ashley GT. The relationship between the pattern of ossification and the definitive shape of the mesosternum in man. J Anat 1956;90:87-105.

13. Wong M, Carter DR. Mechanical stress and morphogenetic endochondral ossification of the sternum. J Bone Joint Surg 1988;70:992-1000.

14. Lai HC, Kosorok MR, Sondel SA, et al. Growth status in children with cystic fibrosis based on the National Cystic Fibrosis Patient Registry data: Evaluation of various criteria used to identify malnutrition. J Pediatr 1998;132:478-85.

15. Patel L, Dixon M, David TJ. Growth and growth charts in cystic fibrosis. J Royal Soc Med 2003:96(Suppl):35-41.

16. Mullis PE, Liechti-Gallati S, Di Silvio L, Brook CG, Paes-Alves AF. Short stature in a patient with cystic fibrosis caused by a $6.7-\mathrm{kb}$ human growth hormone gene deletion. Hormone Res 1991;36:4-8.

17. Schnabel D, Grasemann C, Staab D, Wollmann H, Ratjen F. A multicenter, randomized, double-blind, placebo-controlled trial to evaluate the metabolic and respiratory effects of growth hormone in children with cystic fibrosis. Pediatrics 2007;119:e1230-8.

18. Tanner JM, Whitehouse RH, Hughes PCR, Carter BS. Relative importance of growth hormone and sex steroids for the growth at puberty of trunk length, limbs length and muscle width in growth hormone-deficent children. Pediatrics 1976;89:1000-8.

19. Binder G. Short stature due to SHOX deficency: Genotype, phenotype, and therapy. Horm Res Paediatr 2011;75:81-9. 


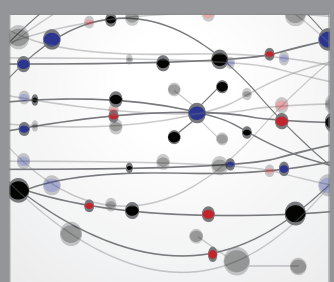

The Scientific World Journal
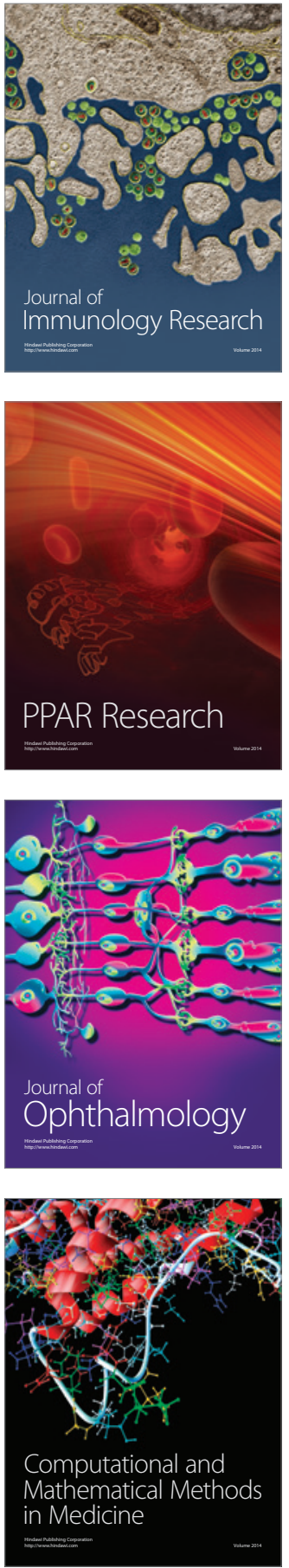

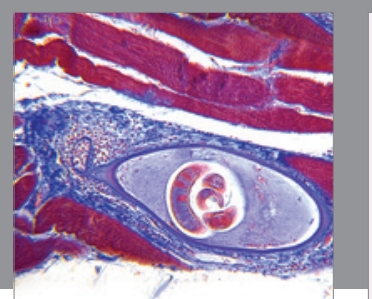

Gastroenterology Research and Practice

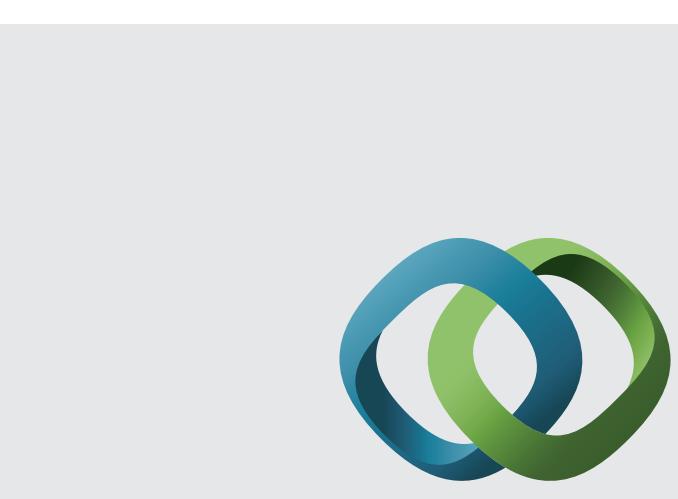

\section{Hindawi}

Submit your manuscripts at

http://www.hindawi.com
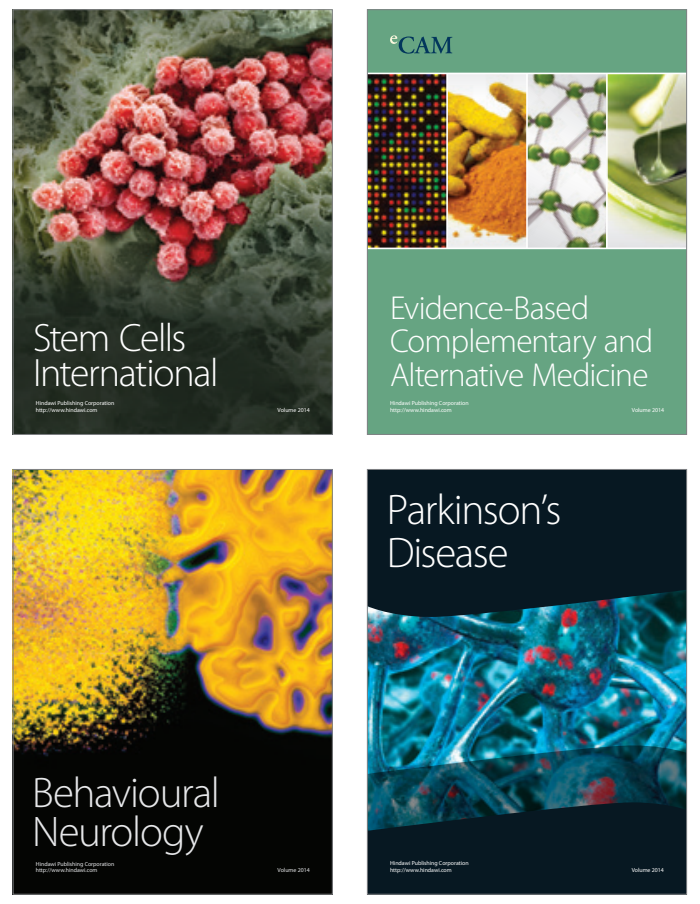
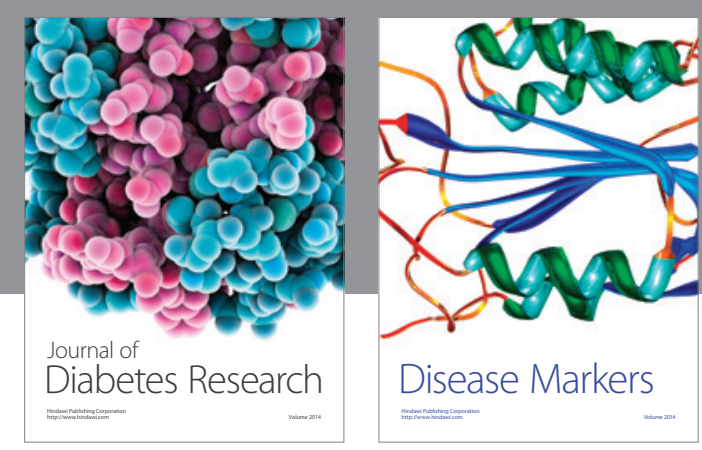

Disease Markers
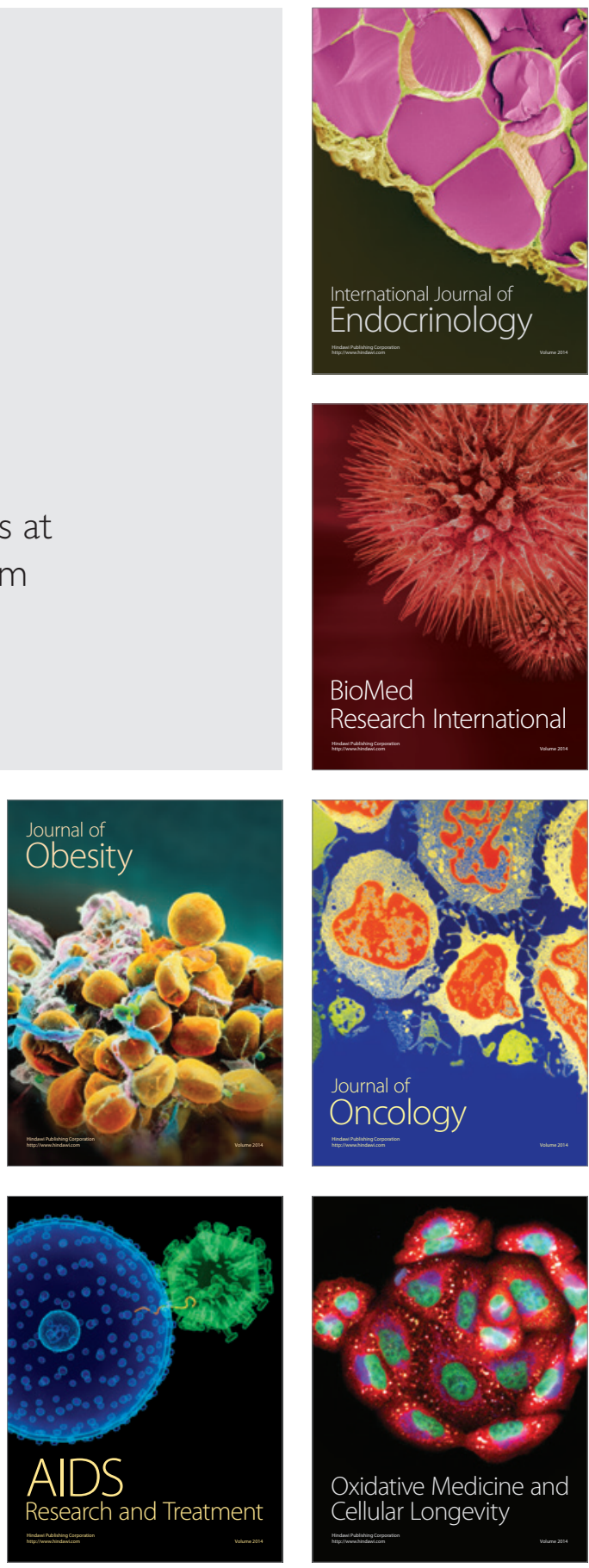